\section{Effects of a Short Interpregnancy interval on Pregnancy Outcomes}

Islam Abozeid ${ }^{1, *}$ M.B.B.Ch, Hosam Al-Din Hussein Kamel Salem ${ }^{1}$ MD, Adel Aly Elboghdady ${ }^{1}$ MD

* Corresponding Author:

Islam Abozeid

dr.islam.abouzeid@gmail.com

Received for publication March 29, 2021; Accepted May 28, 2021; Published online May 28, 2021

Copyright The Authors published by Al-Azhar University, Faculty of Medicine, Cairo, Egypt. Users have the right to read, download, copy, distribute, print, search, or link to the full texts of articles under the following conditions: Creative Commons Attribution-Share Alike 4.0 International Public License (CC BY-SA 4.0).

doi: 10.21608/aimj.2021.69103.1444

${ }^{1}$ Obstetrics and Gynecology Department, Faculty of Medicine, Al-Azhar University Cairo, Egypt.

Disclosure: The authors have no financial interest to declare in relation to the content of this article. The Article Processing Charge was paid for by the authors.

Authorship: All authors have a substantial contribution to the article.

\begin{abstract}
Background: Birth spacing is an important subject that is put into consideration by obstetricians to be discussed with women who are thinking about getting pregnant. A decision that is taken by a couple to plan or postpone a pregnancy is affected by many factors. These factors can include the age of the couples, availability of family planning counseling, last pregnancies outcome, cultural aspects, religious beliefs, personal preference, fecundity and fertility aspirations.

Aim of the work: To investigate the effects of a short interpregnancy interval on the subsequent pregnancy.

Patients and methods: This study is designed as retrospective cohort study at obstetrics and gynecology department at EL-Sayed Galal university hospital and El-Monira general hospital between January 2020 till December 2020.

Results: The results of this study showed that there were no any differences of great significance between the studied groups regarding the maternal complications. The results of this study showed that preterm labor, babies of SGA, LBW and Jaundice were linked to the Short IPI group.

Conclusion: One of the most important subjects in obstetric practice is birth spacing. In this study we have investigated the effects of a short inter-pregnancy interval on the pregnancy outcomes and what possible determinants there are for a short IPI. After analyzing the results of this study, the following conclusions were made: A short IPI was associated with Small-for-Gestational age babies. This finding can impact neonatal morbidity. So, one of the ways to prevent SGA and other unfavorable neonatal outcomes is to advise women of reproductive age about the importance of adequately spacing their children. In our study; Breastfeeding and the use of contraceptive methods were factors associated with a longer IPI.
\end{abstract}

Keywords: Interpregnancy interval, inter-outcome interval, inter-delivery interval.

\section{INTRODUCTION}

Birth spacing is an important subject that is put into consideration by obstetricians to be discussed with women who are thinking about getting pregnant. A decision that is taken by a couple to plan or postpone a pregnancy is affected by many factors. These factors can include the age of the couples, availability of family planning counseling, last pregnancies outcome, cultural aspects, religious beliefs, personal preference, fecundity and fertility aspirations. ${ }^{1}$

Birth spacing is defined in many different terms including birth to pregnancy interval (BTP), interdelivery interval (IDI), inter-outcome interval (IOI) or interpregnancy interval (IPI). Definition of interpregnancy interval is the time in-between a live birth and the next pregnancy. The same definition goes for birth to pregnancy interval. IDI's definition is the time in-between two successive live births. This may also be named birth-to-birth interval. IPI equals IDI minus forty weeks. Inter-outcome interval's definition is the time in-between an outcome of one pregnancy and the next, regardless of the outcome of this pregnancy. IOI gives better assessment of risk for stillbirth and abortions whether induced or spontaneous. ${ }^{2}$

In June 2005 the WHO gathered a team of birth spacing experts in Geneva. ${ }^{3}$ After they reviewed all studies available, they agreed that an interpregnancy interval between eighteen \& twenty-seven months was believed to have better outcomes. This group of consultants agreed on and gave recommendations that at least 24 months IPI to prevent maternal and perinatal adverse outcomes.

It has been reported that IPI affects the subsequent pregnancy outcome. Both short interpregnancy interval (less than twenty-four months) and long interpregnancy interval (more than sixty months) have been linked to adverse outcomes of the subsequent pregnancy, most of them are linked with short IPIs between pregnancies. ${ }^{4}$

Increased risk of many obstetric complications has been linked to short IPI including preterm prelabour rupture of membranes, preterm birth, small for gestational age (SGA), low birth weight, labour dystocia, maternal morbidity and mortality. ${ }^{5}$

The Increased risk of many obstetric complications linked to short IPI is believed to be due to different 
mechanisms that may include nutritional status of the mother and depletion of folate reserve, postpartum hormonal imbalance and lactation stress. ${ }^{6}$

Folate depletion might not be replenished in a sufficient way between pregnancies if they were closely spaced, especially if the mother was breastfeeding, and this may cause adverse pregnancy outcomes. $^{7}$

The IPI should not be isolately reviewed and is the outcome of many circumstances that affect the mother and the family. Many factors in published literature were described to determine birth spacing. For example, in some rural places, where the access to contraceptives is not possible, so women tend to rely on the breastfeeding of their current new born to postpone the next pregnancy (lactational amenorrhoea method). ${ }^{8}$

Lactational amenorrhea method can only be relied on if the baby is exclusively breastfed for the first six months of life or the shortage of contraception will lead to a short IPI. Some other factors that were suggested are infectious processes that can extend from a previous birth to the subsequent pregnancy that may contribute a link between short IPI and adverse pregnancy outcomes. ${ }^{9}$

Incompletely resolved genital tract inflammations that were developed in the previous pregnancy is believed to be the link between short IPI, PPROM and subsequent preterm birth. ${ }^{10}$

\section{PATIENTS AND METHODS}

Setting of the study: This study is designed as retrospective cohort study at obstetrics and gynecology department at EL-Sayed Galal university hospital and El-Monira general hospital between January 2020 till December 2020.

Population of the study: This study included 250 women. They were recruited from labour ward records. And they were divided into 2 groups: Group A: Short interpregnancy interval "less than twentyfour months” included 86 patients Group B: Long interpregnancy interval "more than twenty-four months" included 164 patients

Recruitment: Potential participants are identified from labor ward records and will be only contacted post-delivery. They will be then approached by our research team and recruited after explanation of the study. No recruitment during labor is allowed.

Inclusion criteria: Women 18 years and older. Patients with parity more than 1 , postnatal patients. All modes of delivery will be recruited. All pregnancy outcomes will be included. Women willing to participate in the study and who can understand the study.

Exclusion criteria: Primigravida women. Women who will elect not to be interviewed or can't understand the study. Patients who will refuse to sign the consent.

Study Method: The main objective of the study is to assess the effects of a short interpregnancy interval (less than 24 months) on pregnancy outcomes compared to women who are having a longer IPI of more than 24 months and to investigate any factors that may possibly influence timing of the pregnancies.

All patients in this study were subjected to the following: Informed consent: Informed written consents were obtained from patients who are included in the study.

Complete History Taking Including: Personal history: This included name, age, duration of marriage, last menstrual period, parity, occupation and special habits. Contraceptive history Obstetric history including: $\square$ Full details of $p$ pregnancies (Date, outcome, onset and mode of delivery, gestational age at delivery, any associated complication and spacing between each pregnancy. History of present pregnancy outcome including: fetal and maternal outcomes

General Examination included: Weight, height, body Mass Index (BMI), temperature, pulse, blood pressure, chest and cardiac examination, signs of anemia.

Routine Laboratory investigations: Complete blood count: (RBCs, WBCs, Platelet count, $\mathrm{Hb} \%$, Hemoglobin concentration). Complete urine. Renal function tests: (serum creatinine, creatinine clearance). Liver function tests: (SGOT and SGPT). Fasting and 2 hours post prandial sugar.

\section{Statistical methods}

The collected data was coded, tabulated, and statistically analyzed using IBM SPSS statistics (Statistical Package for Social Sciences) software version 22.0, IBM Corp., Chicago, USA, 2013 and Microsoft Office Excel 2007. Descriptive statistics was done for quantitative data as minimum\& maximum of the range as well as mean \pm SD (standard deviation) for quantitative normally distributed data, while it was done for qualitative data as number and percentage. Inferential analyses were done for quantitative variables using ShapiroWilk test for normality testing, independent t-test in cases of two independent groups with normally distributed data. In qualitative data, inferential analyses for independent variables was done using Chi square test for differences between proportions and Fisher's Exact test for variables with small expected numbers. While correlations was done using Pearson correlation for numerical normally distributed data. The level of significance was taken at $\mathrm{P}$ value $<0.050$ is significant, otherwise is nonsignificant.

\section{RESULTS}

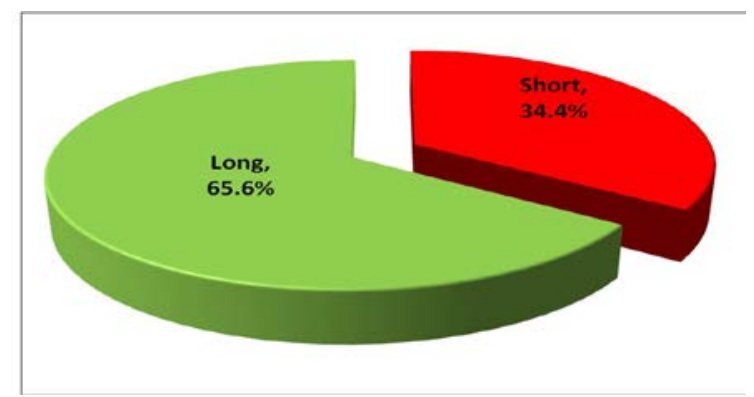

Fig. 1: Interpregnancy interval among the studied cases. 


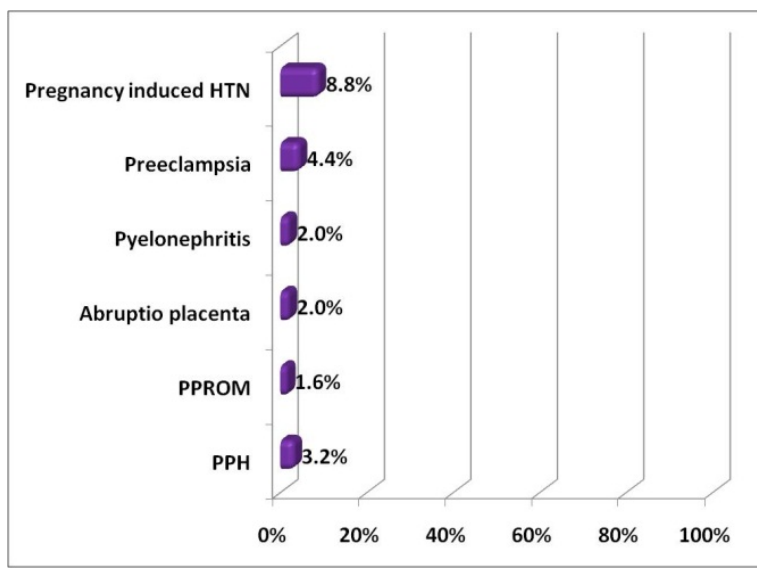

Fig. 2: Maternal complications among the studied cases

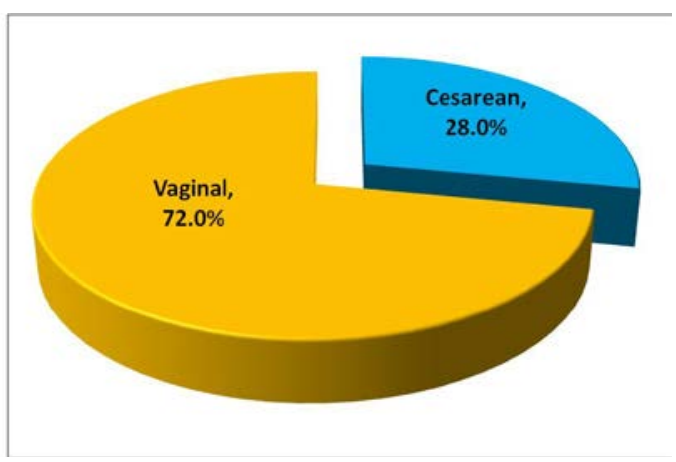

Fig. 3: Mode of delivery among the studied cases

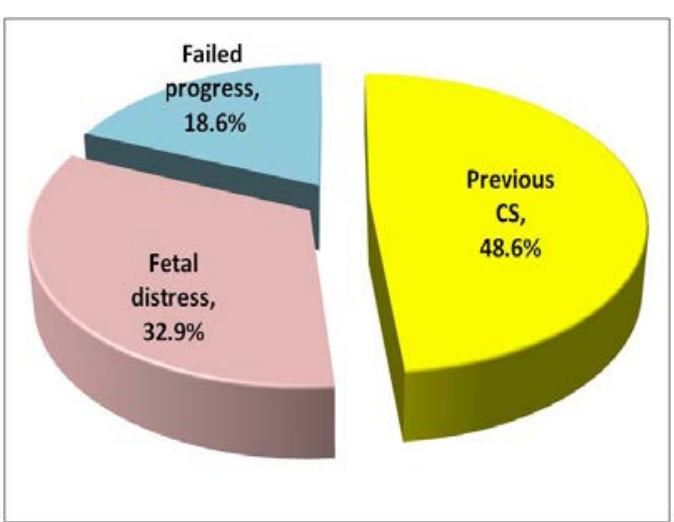

Fig. 4: Indications of cesarean delivery among the studied cases

\begin{tabular}{|c|c|c|c|}
\hline \multicolumn{2}{|c|}{ Variables } & Mean \pm SD & Range \\
\hline \multicolumn{2}{|c|}{ GA (weeks) } & $38.7 \pm 1.4$ & $36.0-42.0$ \\
\hline \multirow{2}{*}{ Time } & Preterm & 17 & $\%$ \\
\cline { 2 - 4 } & Term & 233 & 93.2 \\
\hline
\end{tabular}

Total $=250$.

Table 1: Delivery time among the studied cases show that: Preterm delivery was in less than one tenth of the studied cases.

\begin{tabular}{|c|c|c|}
\hline Variables & $\begin{array}{c}\text { Mean } \pm \text { S } \\
\mathrm{D}\end{array}$ & Range \\
\hline Birth weight (kg) & $3.0 \pm 0.5$ & $\begin{array}{c}1.3- \\
4.2\end{array}$ \\
\hline & $\mathrm{N}$ & $\%$ \\
\hline Small for gestational age (SGA) & 29 & 11.6 \\
\hline Low birth weight (LBW) & 32 & 12.8 \\
\hline Macrosomia & 2 & 0.8 \\
\hline $\begin{array}{c}\text { Respiratory distress syndrome } \\
\text { (RDS) }\end{array}$ & 10 & 4.0 \\
\hline Jaundice & 21 & 8.4 \\
\hline
\end{tabular}

Total $=250$.

Table 2: Neonatal complications among the studied cases show that: Low birth weight was the most frequent neonatal complications.

\begin{tabular}{|c|c|c|c|c|c|}
\hline \multicolumn{2}{|c|}{ Variables } & $\begin{array}{c}\text { Short } \\
(\mathrm{N}=86)\end{array}$ & $\begin{array}{c}\text { Long } \\
(\mathrm{N}=164)\end{array}$ & Test & P-value \\
\hline \multirow{3}{*}{\multicolumn{2}{|c|}{$\frac{\left(\mathrm{kg} / \mathrm{m}^{2}\right)}{\text { Parity }}$}} & $28.7 \pm 3.0$ & $32.2 \pm 3.5$ & $\mathrm{t}=7.966$ & $<0.001^{* *}$ \\
\hline & & $25.1 \pm 2.4$ & $26.5 \pm 2.7$ & $t=4.071$ & $<0.001^{* *}$ \\
\hline & & $2.8 \pm 0.8$ & $3.3 \pm 1.0$ & $t=3.375$ & $<0.001^{* *}$ \\
\hline \multirow{2}{*}{$\begin{array}{l}\text { Last mode } \\
\text { of delivery }\end{array}$} & Cesarean & $21(24.4 \%)$ & $34(20.7 \%)$ & \multirow{2}{*}{$\chi^{2}=0.447$} & \multirow{2}{*}{0.504} \\
\hline & Vaginal & 65 (75.6\%) & 130 (79.3\%) & & \\
\hline
\end{tabular}

t: Independent t-test. $\chi 2$ :Chi square test.

$$
\text { **Highly significant }<0.001
$$

Table 3: Comparison according to interpregnancy interval regarding demographic characteristics show that: Cases with short IPI significantly had lower age, BMI and parity.

\begin{tabular}{|c|c|c|c|c|c|}
\hline Variables & $\begin{array}{c}\text { Short } \\
(\mathrm{N}=86)\end{array}$ & $\begin{array}{c}\text { Long } \\
(\mathrm{N}=164)\end{array}$ & $\begin{array}{c}\text { Test } \\
\text { value }\end{array}$ & $\begin{array}{c}\text { P- } \\
\text { value }\end{array}$ & $\begin{array}{c}\text { Relative } \\
\text { risk } \\
(95 \% \mathrm{Cl})\end{array}$ \\
\hline $\begin{array}{c}\text { Pregnancy induced } \\
\text { HTN }\end{array}$ & $6(7.0 \%)$ & $\begin{array}{c}16 \\
(9.8 \%)\end{array}$ & $\chi^{2}=0.543$ & 0.461 & $\begin{array}{c}0.72(0.29- \\
1.76)\end{array}$ \\
\hline Preeclampsia & $2(2.3 \%)$ & $9(5.5 \%)$ & $\chi^{2}=1.341$ & 0.247 & $\begin{array}{c}0.42(0.09- \\
1.92)\end{array}$ \\
\hline Pyelonephritis & $1(1.2 \%)$ & $4(2.4 \%)$ & $\chi^{2}=0.469$ & 0.494 & $\begin{array}{c}0.48(0.05- \\
4.20)\end{array}$ \\
\hline PPROM & $3(3.5 \%)$ & $1(0.6 \%)$ & $\chi^{2}=2.969$ & 0.085 & $\begin{array}{c}5.72(0.60- \\
54.17)\end{array}$ \\
\hline Abruptio placenta & $3(3.5 \%)$ & $2(1.2 \%)$ & $\chi^{2}=1.483$ & 0.224 & $\begin{array}{c}2.86(0.49- \\
16.79)\end{array}$ \\
\hline PPH & $4(4.7 \%)$ & $4(2.4 \%)$ & $\chi^{2}=0.891$ & 0.345 & $\begin{array}{c}1.91(0.49- \\
7.44)\end{array}$ \\
\hline
\end{tabular}

$\chi 2$ : Chi square test

Table 4: Comparison according to interpregnancy interval regarding maternal complications show that: No significant differences according to interpregnancy interval regarding maternal complications.

\begin{tabular}{|c|c|c|c|c|c|c|}
\hline \multicolumn{2}{|c|}{ Findings } & $\begin{array}{c}\text { Short } \\
(\mathrm{N}=86)\end{array}$ & $\begin{array}{c}\text { Long } \\
(\mathrm{N}=164)\end{array}$ & $\begin{array}{c}\text { Test } \\
\text { value }\end{array}$ & $\begin{array}{c}\text { P- } \\
\text { value }\end{array}$ & $\begin{array}{c}\text { Relative risk } \\
(95 \% \mathrm{Cl})\end{array}$ \\
\hline $\begin{array}{c}\text { Mode of } \\
\text { Delivery }\end{array}$ & Cesarean & $34(39.5 \%)$ & $36(22.0 \%)$ & \multirow{2}{*}{$\chi^{2}=8.652$} & $0.003 *$ & $\begin{array}{c}1.80 \\
(1.22-2.66)\end{array}$ \\
\cline { 2 - 7 } & Vaginal & $52(60.5 \%)$ & $128(78.0 \%)$ & &
\end{tabular}

$\chi 2$ :Chi square test. *Significant

Table 5: Comparison according to interpregnancy interval regarding mode of delivery show that: Cases with short IPI significantly had more frequent cesarean delivery. 


\begin{tabular}{|c|c|c|c|c|c|c|}
\hline \multicolumn{2}{|c|}{ Variables } & $\begin{array}{c}\text { Short } \\
(\mathrm{N}=86)\end{array}$ & $\begin{array}{l}\text { Long } \\
(\mathrm{N}=164)\end{array}$ & $\begin{array}{c}\text { Test } \\
\text { value }\end{array}$ & $P$-value & $\begin{array}{c}\text { Mean } \pm S \\
E \\
(95 \% \mathrm{Cl}\end{array}$ \\
\hline \multicolumn{2}{|c|}{ GA (weeks) } & $\begin{array}{c}38.3 \pm 1 \\
5\end{array}$ & $38.9 \pm 1.2$ & $\mathrm{t}=3.414$ & ${ }^{\wedge} 0.002^{*}$ & $\begin{array}{r}-0.6 \pm 0.2 \\
-1.0-0.3\end{array}$ \\
\hline & & & & & & $\begin{array}{c}\text { Relative } \\
\text { risk } \\
(95 \% \mathrm{Cl})\end{array}$ \\
\hline \multirow{2}{*}{ Time } & Preterm & $\begin{array}{c}15 \\
(17.4 \%)\end{array}$ & $2(1.2 \%)$ & \multirow{2}{*}{$\begin{array}{c}x^{2}=23.42 \\
6\end{array}$} & \multirow{2}{*}{$\begin{array}{c}<0.001^{*} \\
*\end{array}$} & \multirow{2}{*}{$\begin{array}{l}14.30 \\
(3.35- \\
61.10)\end{array}$} \\
\hline & Term & $\begin{array}{c}71 \\
(82.6 \%)\end{array}$ & $\begin{array}{c}162 \\
(98.8 \%)\end{array}$ & & & \\
\hline
\end{tabular}

t: Independent t-test. $\chi 2$ : Chi square test. ${ }^{*}$ Significant $<0.050$. **Highly significant $<0.001$. SE: Standard error. CI: Confidence interval

Table 6: Comparison according to interpregnancy interval regarding delivery time show that: Cases with short IPI significantly had more frequent preterm delivery.

\begin{tabular}{|c|c|c|c|c|c|}
\hline Variables & $\begin{array}{l}\text { Short } \\
(N=86)\end{array}$ & $\begin{array}{c}\text { Long } \\
(\mathrm{N}=164) \\
\end{array}$ & $\begin{array}{c}\text { Test } \\
\text { value }\end{array}$ & P-value & $\begin{array}{r}\text { Mean } \pm \text { SE } \\
(95 \% \mathrm{Cl})\end{array}$ \\
\hline \multirow[t]{2}{*}{ Birth weight (kg) } & $2.8 \pm 0.6$ & $3.0 \pm 0.4$ & $\mathrm{t}=3.810$ & $\wedge 0.001 *$ & $\begin{array}{l}-0.2 \pm 0.1 \\
-0.4--0.1\end{array}$ \\
\hline & & & & & $\begin{array}{l}\text { Relative } \\
\text { risk } \\
(95 \% \mathrm{Cl}) \\
\end{array}$ \\
\hline $\begin{array}{l}\text { Small for } \\
\text { gestational } \\
\text { age (SGA) }\end{array}$ & $16(18.6 \%)$ & $13(7.9 \%)$ & $\chi^{2}=6.273$ & $0.012^{*}$ & $\begin{array}{c}2.35 \\
(1.18- \\
4.65)\end{array}$ \\
\hline $\begin{array}{c}\text { Low birth weight } \\
\text { (LBW) }\end{array}$ & $19(22.1 \%)$ & $13(7.9 \%)$ & $\chi^{2}=10.143$ & $0.001^{*}$ & $\begin{array}{c}2.79 \\
(1.45-5.37)\end{array}$ \\
\hline Macrosomia & $0(0.0 \%)$ & $2(1.2 \%)$ & $\chi^{2}=1.057$ & 0.304 & -- \\
\hline $\begin{array}{c}\text { Respiratory distress } \\
\text { syndrome (RDS) }\end{array}$ & $6(7.0 \%)$ & $4(2.4 \%)$ & $x^{2}=3.025$ & 0.082 & $\begin{array}{c}2.86 \\
(0.83- \\
9.86) \\
\end{array}$ \\
\hline Jaundice & $12(14.0 \%)$ & 9 (5.5\%) & $\chi^{2}=5.255$ & $0.022^{*}$ & $\begin{array}{c}2.54 \\
(1.12- \\
5.80)\end{array}$ \\
\hline
\end{tabular}

$\mathrm{t}=$ Independent $\mathrm{t}$-test. $\chi 2$ :Chi square test. *Significant $<0.050$. ${ }^{* *}$ Highly significant $<0.001$. SE: Standard error. CI: Confidence interval

Table (7) Comparison according to interpregnancy interval regarding neonatal condition show that: Cases with short IPI significantly had more frequent SGS, LBW and jaundice.

\begin{tabular}{|c|c|c|}
\hline Variables & $\mathrm{r}$ & $\mathrm{p}$ \\
\hline Age & 0.478 & $<0.001^{* *}$ \\
\hline BMI & 0.367 & $<0.001^{* *}$ \\
\hline Parity & 0.244 & $<0.001^{* *}$ \\
\hline GA & 0.278 & $<0.001^{* *}$ \\
\hline Birth weight & 0.344 & $<0.001^{* *}$ \\
\hline
\end{tabular}

Total=250. Pearson correlation. **Highly significant $<0.001$

Table (8) Correlations between interpregnancy interval and age, BMI, parity, GA at delivery \& birth weight show that: There were significant positive correlations between interpregnancy interval and age, BMI, parity, GA at delivery \& birth weight.

\section{DISCUSSION}

A short interpregnancy interval can increase the risk of adverse peri-natal outcomes in the following pregnancy. It could be due to inadequate repletion of nutritional status of the mother following the delivery of a live infant, vertical transmission of infections following a short IPI or increased cervical insufficiency. ${ }^{11}$

It has been found that an IPI of less than six months is associated with (40\%) higher odds of preterm birth, (61\%) higher odds of low birthweight and (26\%) higher odds of SGA in the following pregnancy. Short IPI up to 17 months was also linked to greater risks for these outcomes. These findings and others gave the 2005 World Health Organization (WHO) enough evidence to recommend an IPI of at least 24 months between live birth and following pregnancy in order to decrease the risk of adverse outcomes for the mother and the baby. ${ }^{11}$

One of the Public health goals in the United States is to reduce the prevalence of short spaces between a livebirth and the following pregnancy. This goal's based on so many studies that show how a short interpregnancy interval is linked to higher risks of adverse outcomes of the following pregnancy such as preterm birth. And Unlike other risk factors that can be a cause of adverse pregnancy outcomes, such as the race, or socioeconomic status that cannot be modified, the interpregnancy interval is a very good target as it can be modified by the intervention of public health through improving the access to family planning counselling. ${ }^{12}$

This study included 250 women. They were recruited from labour ward records. And they were divided into 2 groups All patients were subjected to full history taking, full clinical examination, obstetric history, past and present history and routine lab examination.

In this study Cases with short IPI significantly had lower age $(28.7 \pm 3.0)$ in comparison to cases with long IPI (32.2 \pm 3.5$)$ this is consistent with Copen et al. $^{13}$ in which according to a 2015 report by the Center for Disease Control and Prevention in the USA that included birth certificate data from 36 states, about $30 \%$ of American women had a short IPI defined as less than 18 months, which is shorter than the WHO recommended 24 months. From the same study, a short IPI was associated with young maternal age, where more than two-thirds of teenagers aged 15-19 had a short IPI. A long IPI was more common among older women. Our study is also consistent with Appareddy et al. ${ }^{14}$ which found that Women with IPI $<18$ months were of younger age

In this study Cases with short IPI significantly had lower BMI (25.1 \pm 2.4$)$ compared to cases with long IPI (26.5 \pm 2.7$)$.

On the other hand, Appareddy et al. ${ }^{14}$ found that Women with IPI $<18$ months, had higher BMIs.

This study showed no significant differences according to interpregnancy interval regarding maternal complications such as pregnancy induced 
HTN, preeclampsia, pyelonephritis, abruption placenta, PPROM and $\mathrm{PPH}$.

This study doesn't agree with Raj Shree et al, which found that IPI $\leq 6$ months was significantly associated with an increased risk of developing PPROM compared with patients with IPI $\geq 24$ months (odds ratio (OR) 1.80, 95\% CI 1.70-1.90, p <.001). It is also not consistent with Blumenfeld et al. ${ }^{15}$ which reported that a short IPI of less than 6 months was associated with an increased risk of placental abruption. This population-based cohort study (140,577 singleton pregnancies) principally looked at the association of abnormal maternal serum analyte levels (PAPP-A, hCG, AFP, Estriol) and abruptio placentae, and found an increased risk from a short IPI (OR 1.8, 95\% CI 1.2-2.7).

This Study proved that cases with short IPI greatly had more frequent preterm deliveries (17.4\%) compared to cases with long IPI (1.2\%).

Hogue et al also found that risk of preterm birth was increased by approximately $40 \%$ for IPIs of less than 6 months.

This study also agrees with Appareddy et al. ${ }^{14}$ which found that IPI $<18$ months predicted elevated risk for preterm delivery.

In This study, Cases with short IPI (less than 24 months) the incidence of small-for-gestational age (SGA) babies was more significant (18.6\%) compared to long IPI (>24months) (7.9\%).

This is consistent with Conde-Agudelo et al. ${ }^{16}$ which reported that an inter-pregnancy interval of less than 6 months was independently associated with a 30\% increased risk of SGA and inconsistent with De Weger et al. ${ }^{17}$ which found no association between an IPI of less than 6 months and SGA.

Our study revealed that LBW in cases with short IPI was of greater significance $(22.1 \%)$ compared to cases with long IPI (7.9\%) this was also proven by Mahfouz et al. $^{18}$ who found that there was a significant association between LBW and short IPI $(P=0.000)$. The mean birth weight significantly increases as the IPI increases. The mean birth weight of neonates born to women with short IPI was $2.64 \pm$ 0.44 compared to the mean birth weight of optimal and long IPI (3.08 \pm 0.39 and $3.16 \pm 0.39$, respectively) also Several studies in the USA have reported an association between a short IPI and but it is not consistent with Mahande and Obure. ${ }^{19}$ that showed that short interpregnancy intervals $(<24$ months) was associated with low birth weight (OR 1 . 61; 95 \% CI 1 - 34-1.72) and The IPI of 37-59 months or longer were also associated with higher risks of low birth weight which means that both short and long IPI are independent risk factors for adverse pregnancy outcomes.

In This study, babies who were born with jaundice were associated with a short IPI $12(14.0 \%)$ but with long IPI the result was 9 (5.5\%), P value \#0.022*, 2.54 CI (1.12-5.80). Bryant and Madden. ${ }^{20}$ also revealed that short IPI is associated with increased use of health care resources: independent of gestational age, IPI $<6$ months is associated with a greater risk of hospital readmission for neonates. Of 190,889 infants born to mothers meeting inclusion criteria, 20,015 (10\%) were readmitted during the first year of life. The leading diagnoses for these admissions included respiratory (20\%), infectious (12\%), gastrointestinal/ dehydration/nutrition (10\%), jaundice (6\%) and cardiac etiologies (6\%).

In This study, cases with short IPI were delivered by caesarean section more frequently 34 (39.5\%) in comparison to cases with long IPI 36 (22.0\%).

\section{CONCLUSION}

One of the most important subjects in obstetric practice is birth spacing. In this study we have investigated the effects of a short inter-pregnancy interval on the pregnancy outcomes and what possible determinants there are for a short IPI. After analyzing the results of this study, the following conclusions were made: A short IPI was associated with Small-for-Gestational age babies. This finding can impact neonatal morbidity. So, one of the ways to prevent SGA and other unfavorable neonatal outcomes is to advise women of reproductive age about the importance of adequately spacing their children. In our study; Breastfeeding and the use of contraceptive methods were factors associated with a longer IPI.

\section{REFERENCES}

1- Gemmill A and Lindberg LD : Short interpregnancy intervals in the United States. Obstet Gynecol. 2013:122(1):64-71.

2- Thiel de Bocanegra H, Chang R, Howell M, Darney $\mathrm{P}$ : Interpregnancy intervals: impact of postpartum contraceptive effectiveness and coverage. Am J Obstet Gynecol. 2014;210(4):311.

3- WHO : Report of a WHO 2005:technical consultation on birth spacing 2005 [updated June 2005; cited 2015 14 December ]. Available from: http:// www. who. int/ maternal_ child_ adolescent/ documents/ birth_ spacing05/ en/.

4- Conde-Agudelo A, Rosas-Bermudez A, Kafury-Goeta AC : Effects of birth spacing on maternal health: a systematic review. Am J Obstet Gynecol. 2007;196(4):297-308.

5- Zhu BP, Grigorescu V, Le T, Lin M, Copeland G, Barone $\mathrm{M}$, et al. : Labor dystocia and its association with interpregnancy interval. Am J Obstet Gynecol. 2006;195(1):121-8.

6- Basso O, Olsen J, Knudsen LB, Christensen K : Low birth weight and preterm birth after short interpregnancy intervals. Am J Obstet Gynecol. 1998;178(2):259-63.

7- Zhu BP : Effect of interpregnancy interval on birth outcomes: findings from three recent US studies. Int J Gynaecol Obstet. 2005;89 Suppl 1:S25-33. 
8- Sipsma HL, Bradley EH, Chen PG : Lactational amenorrhea method as a contraceptive strategy in Niger. Maternal and Child Health Journal. 2013;17(4):654-60.

9- Himes KP and Simhan HN : Risk of recurrent preterm birth and placental pathology. Obstet Gynecol. 2008;112(1):121-6.

10-Getahun D, Strickland D, Ananth CV, Fassett MJ, Sacks DA, Kirby RS, et al. : Recurrence of preterm premature rupture of membranes in relation to interval between pregnancies. Am J Obstet Gynecol. 2010;202(6):570

11-Katherine AA, Hutcheon JA, Ananth CV, Basso O, Briss PA, Ferré CD, Frederiksen BN, Harper S, Hernández-Díaz S, Hirai AH, Kirby RS : Report of the office of population affairs' expert work group meeting on short birth spacing and adverse pregnancy outcomes: methodological quality of existing studies and future directions for research. Paediatric and perinatal epidemiology. 2019;33(1):O5-14.

12-Kopp DM, Bula A, Maman S, et al. : Influences on birth spacing intentions and desired interventions among women who have experienced a poor obstetric outcome in Lilongwe Malawi: a qualitative study. BMC Pregnancy Childbirth. 2018;18: 197.

13- Copen CE, Thoma ME, Kirmeyer S : Interpregnancy intervals in the United States: data from the birth certificate and the national survey of family growth. Natl Vital Stat Rep. 2015;64(4):1-11.
14- Appareddy S, Pryor J, Bailey B : Inter-pregnancy interval and adverse outcomes: Evidence for an additional risk in health disparate populations. $J$ Matern Fetal Neonatal Med. 2017;30(21):26402644.

15-Blumenfeld YJ, Baer RJ, Druzin ML, El-Sayed YY, Lyell DJ, Faucett AM, et al. : Association between maternal characteristics, abnormal serum aneuploidy analytes, and placental abruption. Am J Obstet Gynecol. 2014;211(2):144-9.

16- Conde-Agudelo A, Belizan JM, Norton MH, RosasBermudez A : Effect of the interpregnancy interval on perinatal outcomes in Latin America. Obstet Gynecol. 2005;106(2):359-66.

17-De Weger FJ, Hukkelhoven CW, Serroyen J, et al. : Advanced maternal age, short interpregnancy interval, and perinatal outcome. Am J Obstet Gynecol. 2011;204:421.

18- Mahfouz EM, El-Sherbiny NA, Wahed WY, Hamed NS : Effect of inter-pregnancy interval on pregnancy outcome: a prospective study at Fayoum, Egypt. Int $J$ Med Dev Ctries. 2018;2(2):38-44.

19-Mahande MJ and Obure J :Effect of interpregnancy interval on adverse pregnancy outcomes in northern Tanzania: a registry-based retrospective cohort study. BMC Pregnancy Childbirth. 2016;16(1):140.

20-Bryant A and Madden E : 541: Short interpregnancy intervals and health services utilization: is neonatal hospital readmission associated with short intervals? American Journal of Obstetrics and Gynecology. 2012;206(1):2. 